\title{
Estudos sobre colonização e imigração no norte do Brasil (1840-1930)
}

\section{Studies on colonization and immigration in Northern Brazil (1840-1930)}

\author{
Fernando da Silva Rodrigues* \\ Érica Sarmiento da Silva**
}

\begin{abstract}
Resumo
Esta pesquisa tem como proposta analisar a participação do Estado brasileiro no processo intervencionista de ocupação da região Norte, face ao projeto político articulado do Império e mais tarde da Primeira República, de imigração e de colonização. Inicialmente, realiza-se um breve panorama, exposto na primeira parte do artigo a partir de bibliografia especializada, acerca das principais correntes migratórias na região Norte do Brasil. A segunda parte do artigo apresenta, de forma introdutória, os resultados de uma pesquisa original, através do levantamento de documentação produzida pela Diretoria Geral de Estatística, por documentos produzidos pelo Ministério da Guerra, e por documentos produzidos pelo Serviço de Povoamento do Solo Nacional, articulando essa produção documental com os interesses modernizadores do Estado no momento em que o país buscava a sua identidade.
\end{abstract}

Palavras-Chaves: imigração; colonização; política.

\begin{abstract}
This research aims to analyze the participation of the Brazilian State in the interventionist process of occupation of the Northern region, in view of the articulated political project of the Empire and later of the First Republic, of immigration and colonization. The investigation was based on documents produced by the General Directorate of Statistics, by the Ministry of War, and by the National Land Settlement Service, articulating this documentary production with the modernizing interests of the State at the time when the country was searching for its identity.
\end{abstract}

Keywords: immigration; colonization; policy.

\footnotetext{
*Doutor em História pela UERJ. Professor do Programa de Pós-Graduação em História da Universidade Salgado de Oliveira. E-mail: fernandoahex@gmail.com

** Doutora em História Contemporânea e de América pela Universidade de Santiago de Compostela. Professora dos Programas de Pós-Graduação em História da Universidade Salgado de Oliveira e da UERJ. E-mail: erisarmiento@gmail.com
} 


\section{Introdução}

Esta investigação tem como proposta analisar, de forma introdutória, a participação do Estado brasileiro no processo intervencionista de ocupação da região Norte, face ao projeto político articulado do Império e mais tarde da Primeira República, de imigração e de colonização.

Incialmente, apresentaremos um breve panorama sobre as principais correntes migratórias na região Norte do Brasil, a partir de uma bibliografia especializada na temática, com o objetivo de oferecer algumas características dos grupos migratórios e analisar, de forma sucinta, a atuação do Estado quanto às políticas de imigração, a partir da criação de colônias e do povoamento das áreas do interior, assim como do estímulo dessas políticas nacionais à chegada de milhares de imigrantes espontâneos. ${ }^{1}$

Com relação ao processo de colonização, buscaremos compreender o modo como o espaço foi ocupado e identificar alguns agentes que atuaram neste processo. Para Fernand Braudel, ${ }^{2}$ os modelos mais importantes de colonização foram os dirigidos pelos Estados nacionais em seus territórios, como parte formativa da nação. Para Jobson Arruda, a expressão colono deve referir-se àquele cuja partida se integra em iniciativas do Estado ou por ele apoiados. ${ }^{3}$ Alguns importantes autores de estudos migratórios, como o historiador português Jorge Fernandes Alves explica, que a palavra emigrante deve ser reservada para os que partem por livre iniciativa, independentemente da orientação do Estado ou até contra as disposições deste: enquanto a expressão colono deve referir-se àquele cuja partida se integra em iniciativas do Estado ou por ele apoiados. ${ }^{4}$

No caso da colonização no Brasil, o Estado é o principal interessado no processo, cedendo desta forma os agentes mais importantes, como foi o caso dos militares, que agiram através de uma política intervencionista, bem como na utilização de mecanismos de controle do espaço e da população local das fronteiras Norte. Já para Moraes ${ }^{5}$ seriam as razões externas que constituiriam

\footnotetext{
${ }^{1}$ São aqueles que emigravam com recursos próprios, sem depender das políticas de subsídios dos Estados. ${ }^{2}$ BRAUDEL, Fernand. Gramática das Civilizações. São Paulo: Martins Fortes, 1989, p. 419.

${ }^{3}$ ARRUDA, José Jobson de Andrade. Os portugueses no Brasil, de colonos a imigrantes: reflexões teóricas. In: ARRUDA, José Jobson de Andrade et all. De colonos a imigrantes. I(E) migração portuguesa para o Brasil. São Paulo: Alameda, 2013, p. 13-20.

${ }^{4}$ Citado por ARRUDA, José Jobson de Andrade. Os portugueses no Brasil, de colonos a imigrantes: reflexões teóricas. In: ARRUDA, José Jobson de Andrade et all. De colonos a imigrantes. I(E) migração portuguesa para o Brasil. São Paulo: Alameda, 2013, p. 18.

${ }^{5}$ MORAES, Antonio Carlos Robert. Território e História no Brasil. 2ª Ed. São Paulo: Annablume, 2005, p. 63.
} 
os fatores principais, que levaram à expansão territorial. $\mathrm{O}$ autor vê na forma de uso do solo, na apropriação da terra e nos assentamentos respostas às motivações externas das metrópoles de ocupação. A colonização exigiria um assentamento humano, que marcaria a presença do agente do Estado no território ocupado.

Quanto aos procedimentos metodológicos, a pesquisa apoiou-se no uso de documentação produzida pela Diretoria Geral de Estatística, para analisar o processo imigratório para a região Norte; por documentos produzidos pelo Ministério da Guerra, principalmente dos relatórios ministeriais, que ajudaram na investigar sobre a implantação de Colônias Militares, no século XIX; e por documentos produzidos pelo Serviço de Povoamento do Solo Nacional, responsável em organizar o processo de imigração e colonização no Brasil República. Dessa forma, objetivamos articular essa produção documental com os interesses modernizadores do Estado português, e posteriormente, do Estado brasileiro, na formação do território e na formação social através da intervenção regional e de uma política relacionada à ocupação do espaço.

$\mathrm{O}$ uso da documentação escrita (manuscrita e impressa) e das análises elaboradas durante a investigação muito contribuíram para a confecção deste trabalho. É importante frisar que o acervo no qual trabalhamos, até os dias atuais, teve pouca procura para realização de trabalhos acadêmicos relacionados à pesquisa articulada entre imigração e colonização militar. As fontes receberam tratamento qualitativo. A abordagem qualitativa, realizada através da análise intratextual, visou investigar as fontes bibliográficas, os acervos pessoais, e os relatórios emitidos pelos diversos órgãos ministeriais, cujos textos foram observados enquanto discurso de época a ser compreendido e questionado quanto à formulação dos atores políticos, ao papel das elites e à construção do Estado.

Colonização, militares, fronteiras, e imigração são temas importantes para se entender a formação de parte do território brasileiro. Articulados, esses temas sinalizam a dinâmica da política de Estado implantada na América portuguesa, para ocupar e defender o território.

\section{As migrações internacionais no contexto político brasileiro na Grande Imigração (1890-1930): breve análise das imigrações no Norte do país}

A imigração é um fenômeno que faz parte da história da América Latina, principalmente ao longo do século XIX e XX, no período da Grande Imigração, entre 1880-1930, e no contexto posterior à Segunda Guerra Mundial, quando muitos imigrantes procedentes da Europa se deslocaram paras as Américas. 0 
ritmo da migração europeia intensificou-se durante o último quartel do século XIX e atingiu seu pico nas duas primeiras décadas do século XX. Entre os anos de 1881 e 1915, cerca de 31 milhões de imigrantes chegaram às Américas, sendo que 4,2 milhões para Argentina e 2,9 milhões para o Brasil. ${ }^{6}$ Argentina e Brasil foram dois países grandes receptores de imigrantes, com fortes programas de incentivo à entrada de estrangeiros. A política imigratória brasileira apostou em uma política mais ativa no exterior, divulgando, através de seus cônsules e representantes, as intenções do governo de conceder aos emigrantes vantagens em relação ao deslocamento e à acomodação do contingente europeu no país. ${ }^{7}$ Outros países do Cone Sul, como a Argentina, adotaram medidas similares, e criou vários projetos estimulando a entrada de mão de obra europeia, como por exemplo, o Proyecto de ley para el fomento a la inmigración y promoción de la colonización, do ano de $1875 .^{8}$

Nesse período, os países europeus vivenciaram diferentes processos de transição demográfica, caracterizados pelo contemporâneo aumento das taxas de natalidade e o decréscimo das taxas de mortalidade, trazendo como consequência a aceleração do crescimento populacional. Esses processos aliados às mudanças pelas quais passava o capitalismo, em decorrência da Segunda Revolução Industrial, ocasionaram uma acentuação nas emigrações europeias, a partir da segunda metade do século XIX. A expansão da superfície cultivada e ocupada respondeu ao crescimento da demanda gerada pelo mundo industrializado. Tal como demonstrou Verónica Secreto em seu livro Fronteiras em movimento. História comparada- Argentina e Brasil no século XIX, o Oeste Paulista e o Sudeste da província de Buenos Aires foram protagonistas do desenvolvimento econômico na segunda metade do século XIX, baseado na incorporação de amplos espaços vazios que passaram a ser ocupados pela produção agropecuária, respondendo à demanda internacional do café, cereais e carne. ${ }^{9}$

Segundo Ramos ${ }^{10}$ a imigração no Brasil, no período da Grande Imigração, está relacionada com duas importantes questões. A primeira diz respeito à

\footnotetext{
${ }^{6}$ KLEIN, Herbert S. Migração Internacional na História das Américas. In: Fausto, Boris (org.) Fazer a América. São Paulo, Edusp, 2000, p.25.

${ }^{7}$ GONÇALVES, Paulo Cesar. Mercadores de braços. Riqueza e acumulação na organização da emigração europeia para o Novo Mundo. São Paulo, Alameda, 2012, p.146.

${ }^{8}$ PÉREZ, Mariana A. Inmigración y colonización. Los debates parlamentários en el siglo XIX. Los polvorines, Universidad Nacional de General Sarmiento; Buenos Aires, Jefatura de Gabinete de Ministros, 2014.

${ }^{9}$ SECRETO, Verônica. Fronteiras em movimento. História comparada - Argentina e Brasil no século XIX. Niterói: Eduff, 2004, p.17.

${ }^{10}$ RAMOS, Jair de Souza, Poder tutelar e formação do Estado brasileiro: o Serviço de Povoamento do Solo
} 
obtenção de um novo tipo de trabalhador, mais adequado às novas relações de trabalho, pelo menos com as áreas mais dinâmicas da economia, que é o regime de trabalho assalariado; e a segunda, está relacionada aos meios pelos quais seria possível manter a oferta de mão-de-obra exigida pelas grandes plantações, num contraste envolvendo terras abundantes e escassez de mão-de-obra. A abolição da escravatura, no entanto, vinha sendo formulada já há algumas décadas, com diversos debates sobre a melhor forma de substituir a mão de obra escrava ocorrendo já nos anos anteriores às décadas de 1870 e $1880 .{ }^{11}$

Vale a pena frisar que nos dois sentidos, a imigração europeia assumiu papel fundamental. No primeiro, foi vista como um instrumento promotor da civilização e da regeneração racial. No segundo, foi, desde o início do período da Grande Imigração, o mecanismo pelo qual era garantida às áreas mais dinâmicas do sistema econômico agrário-exportador a abundância na oferta de mão-de-obra, dirigida e controlada, pelo menos em parte, pelos contratos com as empresas responsáveis pelo financiamento das viagens internacionais. Esse foi o caso, por exemplo, dos italianos em São Paulo. A inserção ocupacional da maioria desse grupo imigratório foi na condição de substitutos efetivos do trabalho escravo nas lavouras. ${ }^{12} \mathrm{Na}$ visão das elites brasileiras, a imigração europeia era um mecanismo de manutenção da oferta de mão-de-obra para a economia agrário-exportadora e de progresso econômico, civilizador e racial, na medida em que o desenvolvimento e a proteção à imigração eram planejados em função de determinados grupos étnicos, diferenciando, assim, os estrangeiros da população brasileira. ${ }^{13}$ Como afirmou Sérgio Buarque de Holanda, o Brasil devia entrar em um novo rumo, porque "se envergonhava de si mesmo, de sua realidade biológica". ${ }^{14}$

Essa dupla interpretação presente na dinâmica dada à política imigratória do governo brasileiro desde a segunda metade do século XIX teve a função

Nacional (1907-1918). In.: LIMA, Antonio Carlos de Souza (org.). Gestar e gerir: estudos para uma antropologia da administração pública no Brasil. Rio de Janeiro: Relume Dumará, 2002, p. 56.

${ }^{11}$ CAMPOS, Gustavo Barreto de Dois séculos de imigração no brasil. A construção da imagem e o papel social dos estrangeiros pela imprensa entre 1808 e 2015. Tese de doutorado. Rio de Janeiro, Universidade Federal do Rio de Janeiro, 2015, p.137.

${ }^{12}$ TRUZZI, Oswaldo. Italianidade no interior paulista. Percursos e caminhos de uma identidade étnica (18801930). São Paulo: Editora Unesp, 2016, p.37.

${ }^{13}$ SEYFERTH, Giralda. Colonização, imigração e a questão racial no Brasil. Revista USP, São Paulo, n. 53, p. 117-149, março-maio, 2002, p.117-149

${ }^{14}$ HOLANDA, Sérgio Buarque de. Raízes do Brasil. 26a ed. São Paulo, Companhia das Letras, 1995, p.166 
de manter a necessidade de mão-de-obra nas áreas produtoras e ocupar com imigrantes europeus, determinadas regiões do Brasil despovoadas. ${ }^{15}$

A imigração subsidiada do Estado de São Paulo é um claro exemplo disso. Atraiu milhares de imigrantes, principalmente espanhóis, portugueses e italianos, dispostos a abandonar seu país para trabalhar nas lavouras cafeeiras. Este tipo de imigração oferecia novas oportunidades ao colono europeu. Uma delas é que estaria livre da necessidade de pagar a passagem, que passaria a ser subvencionada pelos cofres públicos. O governo paulista, assim, custeava uma parte do bilhete, dava a oportunidade do imigrante trazer toda a família e prometia inúmeras vantagens de enriquecimento e posse de terras. Entretanto, a realidade se apresentava bem diferente do cenário proposto, pois a política latifundiária brasileira não possibilitava o fácil acesso dos imigrantes às terras. Por exemplo, em 1850, com o início da chamada Lei de Terras, proibiu-se a aquisição de propriedades por nacionais e qualquer estrangeiro se não fosse através da compra. Competir com as tradicionais famílias oligárquicas, que manipulavam a máquina administrativa e judiciária constituía-se em uma difícil tarefa para o estrangeiro recém-chegado, que só trazia a sua força de trabalho como capital. ${ }^{16}$ Segundo Ligia Osorio Silva, a lei de terras tem suma relevância por ser um marco de transição entre a forma de apropriação territorial da sociedade colonial e a moderna propriedade territorial. ${ }^{17}$ Após a regulamentação da Lei, em 1854, verificou-se um incremento das relações entre o Estado e particulares (agências, companhias e indivíduos) para a introdução de imigrantes e para a colonização de novas áreas. ${ }^{18}$

A partir de 1855, o Governo aprovou os estatutos da intitulada Associação Central de Colonização. Os estatutos contavam com um amplo programa de imigração, que incentiva a vinda de colonos, a compra de terras devolutas para a colonização e a preocupação com a acomodação e cuidados dos colonos que vinham para o Brasil. Dois anos depois, em 1857, o Governo assinou um contrato para receber 50 mil colonos durante o período de cinco anos com subvenção por parte do governo. Em 1874, inaugurou-se uma nova fase na política imigratória brasileira, com a introdução de grandes contratos para atrair europeus. Segundo Paulo Gonçalves, o Governo introduziu um acordo

${ }^{15}$ GONZÁLEZ MARTÍNEZ, Elda. La inmigración esperada. La política migratória brasileña desde João VI hasta Getulio Vargas. Madrid: Consejo Superior de Investigaciones Científicas, 2003.

${ }^{16}$ FAUSTO, Boris. Brasil, de colônia a democracia. Madrid: Alianza América, 1995, p 108.

${ }^{17}$ Apud. Secreto, Verónica. Fronteiras em movimento. História comparada- Argentina e Brasil no século XIX. Niterói: Eduff, 2004, p.90. Para obter mais informações sobre a Lei de Terra, ver a obra indicada.

${ }^{18}$ GONÇALVES, op. cit., p.140 
com o empresário Joaquim Caetano Pinto, que recrutava italianos, para introduzir 100 mil imigrantes em todo o Império, exceto na província do Rio Grande do Sul. ${ }^{19} \mathrm{O}$ contrato foi considerado de extrema importância para a política imigratória brasileira.

Os primeiros colonos a chegarem às plantações de café do oeste paulista, no final do século XIX, foram os italianos e os portugueses. Os espanhóis chegaram depois desses dois grupos, quando em 1902 o governo italiano proíbe a emigração para o Brasil. Os emigrantes chegavam ao Estado de São Paulo e eram imediatamente levados à Hospedaria do Imigrante, onde passariam seus primeiros dias até que fossem encaminhados para alguma fazenda. Essa emigração estava integrada, em sua maioria, por camponeses andaluzes, jornaleiros desprovidos de terra, que viam nesses contratos a busca de melhores oportunidades e a única alternativa para emigrar. Ao contrário de outros grupos de estrangeiros, como os alemães e os suíços, poucos foram os espanhóis que conseguiram adquirir propriedades no Brasil, porque a maioria não possuía capitais para comprar terras e o trabalho nos cafezais não lhes proporcionava o suficiente para isso. A passagem acabou saindo cara para muitos imigrantes, que desprotegidos nas mãos dos fazendeiros, se viram obrigados a obedecer a seus mandos, vivendo isolados sob o controle dos poderosos coronéis brasileiros. ${ }^{20}$

A expansão das plantações cafeeiras gerou riqueza e essa acumulação de capitais propiciou um maior investimento nas cidades, a principal delas, a capital federal, o Rio de Janeiro. Os centros urbanos possuíam outros atrativos para os emigrantes. Se o acesso à terra era difícil e a agricultura não oferecia os benefícios esperados, as cidades ofereciam um setor terciário em expansão e oportunidades de uma ascensão social que aparentemente era mais rápida. Esses imigrantes faziam parte da chamada "imigração espontânea", ou seja, pertenciam àqueles grupos que não dependiam das políticas subsidiadas, mas sim de um planejamento familiar ou de outro tipo de recursos, como o apoio de redes de solidariedade nos países de destino. É o caso, por exemplo, da emigração portuguesa e galega no Rio de Janeiro. Os ibéricos, do Norte da Península, emigravam para as cidades buscando sua principal inserção no pequeno comércio. ${ }^{21}$

\footnotetext{
${ }^{19}$ Ibidem, p.142 e 147.

${ }^{20}$ GONZALEZ MARTINEZ, Elda. Café e Inmigración: los españoles en São Paulo, 1880-1930. Madrid: Cedeal, 1994, p. 84-85.

${ }^{21}$ SARMIENTO, Érica. Galegos nos trópicos: Invisibilidade e presença da imigração galega no Rio de Janeiro (1890-1930). Porto Alegre, EDPucRs, 2017.
} 
Apesar de haver uma grande concentração de pesquisas e estudos dos fluxos migratórios para as regiões sul e sudeste, outras regiões do Brasil também foram receptoras de importantes contingentes, como é o caso da região Norte. Uma característica muito importante dessa região é a sua área fronteiriça, que faz com que haja especial interesse e intervenção por parte do Estado nas políticas migratórias. As regiões de fronteira destacam-se como áreas de intensa circulação cultural, compreendendo vários ciclos migratórios, como os internacionais (a imigração Europa- América), as migrações internas e, também, as que envolvem os países fronteiriços da América do Sul. Sendo assim, essas fronteiras tanto podem se configurar como lugar de controle como de transgressão. ${ }^{22}$

A fronteira é um lugar singular de passagem, mas também de encontros culturais e de relações de identidade. Essa percepção como espaço de contato remete à ideia de movimento e de trocas, o que permite uma compreensão das dinâmicas das migrações sul-americanas e do processo de integração regional. A Amazônia brasileira, por exemplo, acolhe, principalmente, bolivianos $(15,31 \%)$ e peruanos $(13,65 \%)$, e a Amazônia boliviana concentra principalmente brasileiros $(64,43 \%)$ e peruanos $(6,68 \%)$, enquanto a Amazônia peruana recebe principalmente brasileiros $(21,87 \%)$ e colombianos $(20,26 \%){ }_{.23}$

Um balanço da imigração internacional na região pode ser obtido através dos dados sobre o movimento imigratório no porto de Belém, no início do século XX, registrado no Anuário Estatístico do Brasil. ${ }^{24}$ Segundo o Anuário, entre 1908 e 1910, entraram no porto cerca de 13.500 estrangeiros de diversas nacionalidades, destacando-se os portugueses $(48,67 \%)$, os espanhóis $(15,98 \%)$, os ingleses $(7,18 \%)$, os turcos $(4,69 \%)$ e os italianos (4,15\%). Esse contingente migratório só foi superado pelos portos do Rio de Janeiro e de Santos.

A presença estrangeira na Amazônia do final do século XIX e das primeiras décadas do século XX teve, como principal motivação, a busca por riquezas decorrentes da exploração da borracha. Segundo Aragón:

\footnotetext{
${ }^{22}$ ARAGÓN, Luis E. Migração internacional na Pan-Amazônia. Belém, UFPA NAEA, 2009.

${ }^{23}$ Ibidem, p. 14

${ }^{24}$ BRASIL. IBGE. Directoria Geral de Estatística. Annuario Estatistico do Brazil (1908-1912). Rio de Janeiro: Typographia da Estatistica, 1927. Disponível em:

http://seculoxx.ibge.gov.br/images/seculoxx/arquivos_download/populacao/1908_12/ populacao1908_12v1_220.pdf. Acesso em 02/10/2016.

http://seculoxx.ibge.gov.br/images/seculoxx/arquivos_download/populacao/1908_12/ populacao1908_12v1_221.pdf. Acesso em 02/10/2016.

http://seculoxx.ibge.gov.br/images/seculoxx/arquivos_download/populacao/1908_12/ populacao1908_12v1_222_1.pdf. Acesso em 02/10/2016.
} 
Para a Amazônia se dirigiram principalmente portugueses, italianos, espanhóis, e sírio-libaneses, atraídos pela economia da borracha, e na década de 1930 japoneses, por outras razões; mas também havia, na época da borracha, ingleses, franceses, norte-americanos, e de muitas outras regiões e países. Mas ao contrário do que geralmente se pensa, a imigração internacional para a Amazônia se manteve após a decadência da economia da borracha, sendo que foram os estrangeiros, especialmente comerciantes, pequenos industriais e trabalhadores em geral, os grandes responsáveis por sustentar a economia nos anos imediatos após da derrocada da economia da extração do látex. Esses novos migrantes, junto com aqueles que permaneceram, instalaram pequenas fábricas e estabelecimentos comerciais para abastecer o mercado local substituindo produtos que não mais podiam ser importados do mercado europeu. ${ }^{25}$

O censo de 1920, quando a economia da borracha estava em plena decadência, registrou no Pará a soma de 2,25\% estrangeiros, e no Amazonas o total de 4,66\% em relação à população total (983.507 e 363.166, respectivamente). ${ }^{26}$ No caso da Amazônia, e mais especificamente no Pará, apesar dos esforços dos governos da província, no período da borracha, de estabelecer colônias agrícolas com mão-de-obra europeia, os projetos não prosperaram e a migração internacional se deu principalmente de forma espontânea e concentrou-se majoritariamente nas cidades. ${ }^{27}$

Durante a gestão do Governador Lauro Sodré, no Pará, foi promulgada a Lei №. 23, de junho de 1894, que autorizava a introdução de imigrantes no estado. O Estado oferecia o financiamento da passagem do porto de embarque até a cidade de Belém; alojamento gratuito durante o período de 10 dias; transporte até o lugar definitivo de destino; tratamento médico nos núcleos coloniais durante dois anos; concessão gratuita de um lote de 25 hectares, escolhido pelo imigrante, além de ferramentas, e outras concessões. Durante todo o seu mandado, o Governador se empenhou em transformar o Pará em uma terra de imigrantes.

Muitos espanhóis chegaram nessa época ao estado, para trabalharem nas colônias, a maioria procedente da Galicia, mas também havia das províncias de Zamora e Salamanca. ${ }^{28}$ Entretanto, as experiências não foram de todo frutíferas e aqueles espanhóis que tinham algum ofício, como os sapateiros,

\footnotetext{
${ }^{25}$ ARAGÓN, op. cit., p.31.

${ }^{26}$ O declínio do ciclo econômico da borracha iniciou-se entre os anos de 1910 e 1920, quando os comerciantes holandeses e ingleses passaram a explorar economicamente, através de um modelo de produção em larga escala e a custos baixos, a extração e produção da matéria-prima no sudeste asiático.

${ }^{27}$ ARAGÓN, op. cit., p.31.

${ }^{28}$ GONZÁLEZ MARTÍNEZ, Elda. La inmigración esperada. La política migratória brasileña desde João VI hasta Getulio Vargas. Madrid, Consejo Superior de Investigaciones Científicas, 2003, p.126.
} 
ferreiros, pedreiros, etc, decidiram migrar para a capital, Belém. Segundo Elda González, sobre o fracasso da experiência da colônia Benjamin Constant:

... del fracaso eran responsables tanto el gobierno, como el contratista y los propios colonos. El primero porque no contaba con los recursos necessários para llevar adelante el plan (...) el reclutador porque cometió numerosos abusos, entre otros no respetar ça concidicón de que todos los colonos fuesen agricultores; por último, los inmigrantes que no habían unidos sus esfuerzos para conseguir superar las dificultades. ${ }^{29}$

O fluxo imigratório espanhol era formado por grupos familiares que, subsidiados pelo governo paraense, povoaram os núcleos coloniais de Benjamim Constant, Jambuassu, Marapanim, José de Alencar, Santa Rosa, Ferreira Pena e Couto de Magalhães. Segundo Elda González Martínez, os emigrantes que saíam das zonas agrícolas pela falta de perspectiva se dirigiam ao núcleo urbano: a cidade de Belém. Nessa capital, se instalaram também imigrantes espontâneos, que junto com antigos colonos formavam uma comunidade de aproximadamente 3.000 pessoas, procedentes principalmente da província de Ourense. Esses galegos se dedicavam a ofícios manuais, a setores de hotelaria e serviços domésticos. ${ }^{30}$

No caso dos italianos, os projetos de Colonização Agrícola do fim do Império e início da República constituíram a porta de entrada desse grupo na Amazônia, a partir de uma imigração controlada pelo Estado, que favoreceu o desencadeamento de imigrações espontâneas para as cidades amazônicas. Esses grupos de italianos fixaram-se em Belém, Manaus, e em alguns municípios localizados ao longo do rio Amazonas e de seus principais afluentes, por onde circulava o capital mercantil decorrente da economia da borracha. ${ }^{31}$

No caso das colônias italianas, várias foram as experiências vividas por esses imigrantes no Norte do Brasil, como as colônias agrícolas de Anita Garibaldi, Ianetama e Outeiro, localizadas no estado do Pará. As evidências empíricas, para o caso dos italianos, também permitem, agrupá-los em dois grandes segmentos: a imigração subsidiada dirigida para as colônias agrícolas e a imigração espontânea dirigida às cidades. Um dos núcleos coloniais do Pará foi a colônia de Ianatema, um contrato assinado entre o estado do Pará e o armador italiano Salvador Nicosia, em janeiro de 1899, para a introdução de 200 famílias de agricultores italianos. Segundo pesquisa realizada por Maria

\footnotetext{
${ }^{29}$ Ibidem, p.131.

${ }^{30}$ Ibidem, p, 141.

${ }^{31}$ ALIPANDI, E.; MARTINI, V. Gli italiani nel nord Del Brasile. Belém: Typografia da Livraria Gillet, 1932.
} 
Emilia Ferreira Emmi, Salvador Nicosia trouxe para a colônia 48 famílias. No Arquivo Público do Pará, encontram-se as listas nominais dos membros dessas famílias que totalizavam 295 pessoas que embarcaram no porto de Gênova em 1899, com destino a Belém nos navios Rio Amazonas e Rei Umberto da companhia La Ligure Brasiliana.

A contribuição dos italianos nas cidades deu-se com as suas pequenas fábricas de calçados e de bebidas e no comércio de atacado e varejo, sobretudo na exportação de produtos regionais, atividade em que se associavam com os comerciantes portugueses. Sobre a procedência dos que se deslocaram para as cidades amazônicas, Emmi explica:

Embora a origem regional possa pontualmente ser diversificada, a maioria dos imigrantes veio da Itália meridional, principalmente de três regiões, Calábria, Basilicata e Campânia. Entre os meridionais, um grupo se distingue dos demais que por motivações diversas aportaram na Amazônia. Esse grupo apresenta características que o aproximam de uma corrente migratória que na literatura recente sobre imigração italiana vem chamada de imigração calabrolucano-campana. Esse segmento seria formado por pequenos proprietários e artesãos originários da Calabria, Campânia e Basilicata (antiga Lucânia) que com recursos próprios emigraram e se instalaram nas capitais e cidades do Norte e do Nordeste do Brasil. Constituiu um grupo mais numeroso do que o da colonização dirigida para as colônias agrícolas e teve maior continuidade. Seus descendentes ainda são encontrados em várias cidades amazônicas. ${ }^{32}$

A imigração japonesa destacou-se como um claro exemplo de sucesso no empreendimento agrícola para a colonização no Amazonas. Chegaram ao Pará (Tomé-Açú) em 1929 e ao Amazonas em 1929 (Maués) e 1930 (Parintins). Segundo Alfredo Homma, o sucesso da colonização japonesa, decorreu da introdução de recursos da biodiversidade exógena, a qual era normal na época, cujas técnicas de cultivo e beneficiamento introduzidas pelos migrantes japoneses foram aprendidas rapidamente pelos caboclos da Amazônia. ${ }^{33}$

Os imigrantes vincularam-se a diversas atividades dando, portanto, importante contribuição tanto no domínio econômico, quanto no técnico, profissional e cultural. Os ingleses, por exemplo, teriam se destacado na construção de portos, produção de energia, telefonia, telegrafia, saneamento básico, além de significativa participação no setor de comércio e de crédito,

${ }^{32}$ EMMI, Marilia Ferreira. Fluxos migratórios internacionais para a Amazônia brasileira do final do século XIX ao início do século XX: o caso dos italianos. In: Aragón, Luis E. Migração internacional na Pan-Amazônia. Belém, UFPA NAEA, 2009, p.272-273

${ }^{33}$ HOMMA, Alfredo Kingo Oyama. A imigração japonesa na Amazônia (1929-2009): Passado, presente e futuro In: Aragón, op. cit., 2009. 
setor do qual participavam ainda, os estadunidenses e franceses. Os ingleses dominaram a comercialização da borracha e chegaram a instalar uma agência do London Bank of South América, antes de qualquer outra agência bancária nacional. Já os portugueses, na cidade de Belém, destacaram-se pelo seu pioneirismo no setor de aviamento, ganhando grande importância no setor comercial da cidade. ${ }^{34}$ A maior parte desses portugueses, radicados no Pará, era originária das províncias do Douro e do Minho e constituíam-se de homens jovens e solteiros, majoritariamente na faixa dos 20 a 29 anos. ${ }^{35}$ Já a participação de judeus, espanhóis e norte-africanos na Amazônia estavam concentradas principalmente nas atividades de escritório e contabilidade comercial e dos portugueses no comércio por atacado e varejo. ${ }^{36}$

Com as riquezas decorrentes da borracha, o poder público direcionava parte dos recursos financeiros para a implantação de um processo de modernização das cidades. Os migrantes estrangeiros inseriram-se em diferentes setores da economia. Houve experiência, como já mencionamos, na colonização agrícola, entretanto, foi o crescimento urbano que propiciou condições favoráveis para criação de um mercado de atividades de prestação de serviços que atraiu boa parte dos imigrantes que chegavam às cidades. 0 processo de modernização da cidade de Belém, a Belle Époque, só foi possível em razão do enriquecimento que atingiu certos setores sociais da região, através da extração e produção do látex, a partir da segunda metade do século XIX. De 1870 a 1910, considera-se o maior surto econômico já verificado na região, tendo-se como principal indicador o crescente aumento da produção da borracha. ${ }^{37}$ A nova ordem econômica propiciou a composição de uma elite formada por comerciantes, seringalistas, financistas, com destaque para os profissionais liberais. Por outro lado, com as construções e obras públicas nas principais cidades, como Belém e Manaus, surgiu uma nova força de trabalho propriamente urbana, que vai se juntar a outros ofícios, como os alfaiates, sapateiros, relojoeiros, marceneiros entre outros. A composição desses grupos expressava a camada pobre da população. ${ }^{38}$

\footnotetext{
${ }^{34}$ SARGES, Maria de Nazaré. Belem: riquezas produzindo a Belle Époque (1870-1912). 3ª ed. Belém, Paka_Tatu, 2010, p.121 e 123

${ }^{35}$ CANCELA, Cristina Donza. Redes sociais, família e migração portuguesa em uma capital Amazônica: Pará/ Brasil, 1850-1920. In: DALLA-CORTE CABALLERO, Gabriela (coord. y ed.). Familias, movilidad y migración. América Latina y España. Rosario, Prohistoria ediciones, 2015, p. 169-188 (p.155)

${ }^{36}$ EMMI, op. cit., 2009.

${ }^{37}$ SARGES, op. cit., p.94

${ }^{38}$ Ibidem, p.125.
} 


\section{Segundo Maria de Nazaré Sarges:}

Reforçando o processo de inserção da Amazônia no sistema capitalista mundial, toda a atividade econômica da região passou a girar em torno da borracha a partir de 1840. Em decorrência dessa nova ordem econômica, Belém assumiu o papel de principal porto de escoamento da produção gomífera, canalizando parte do excedente que se originou dessa economia para os cofres públicos.... ${ }^{39}$

A partir da década de $1940^{40}$ ocorrerá uma diminuição no ritmo das imigrações europeias, de forma geral, no Brasil, e os censos de 1940 e 1950 revelam, consequentemente, uma acentuada queda na imigração internacional na Amazônia. A redução nos fluxos migratórios faz parte do contexto internacional do Pós- Segunda Guerra Mundial. Com a recuperação da economia europeia e a situação econômica e política desfavorável de muitos países da América Latina, o sonho de "fazer a América" já não era tão convincente.

A partir de 1960, uma importante corrente migratória de portugueses e espanhóis, por exemplo, passaram a eleger os países europeus como destino, reduzindo, assim drasticamente os fluxos para países receptores desses contingentes, como a Argentina e o Brasil. Já no cenário nacional, no Brasil, a partir da década de 1940, haverá um novo ciclo da borracha no Amazonas, que será "alimentando" com as migrações internas da população nordestina. ${ }^{41}$

\section{Aspectos da colonização militar nas fronteiras da Amazônia: ocupação e defesa do território.}

Após o breve panorama, exposto nas páginas acima, sobre algumas das correntes migratórias na região Norte do Brasil, abordaremos neste item, de forma introdutória, a política de colonização desenvolvida pelo Estado brasileiro para essa região, durante o Império e o período da Primeira República, tomando como base o processo de formação do Estado Nacional.

Do ponto de vista mais específico, vale mencionar, ainda que de forma sucinta, as políticas implementadas pelo Império brasileiro no processo de instalação das colônias militares na Amazônia, como forma de povoamento e sob o controle da administração militar. Elas se constituíram em um programa com objetivo de defesa das fronteiras nacionais e de manutenção do

\footnotetext{
${ }^{39}$ Ibidem, p.20.

${ }^{40}$ BRASIL. IBGE. Directoria Geral de Estatística. Censo Demográfico de 1940.

${ }^{41}$ Essa migração, recrutada pelo governo de Getúlio Vargas, ficou conhecida como "soldados da borracha". Sobre o tema ver, entre outros, SECRETO, María Verónica. Soldados da borracha: trabalhadores entre o sertão e a Amazônia no governo Vargas. São Paulo: Editora Fundação Perseu Abramo, 2007.
} 
território. Devemos atentar para o fato da região Norte do Brasil caracterizar-se pela sua ampla extensão fronteiriça, e toda a transitoriedade que isso implica, possibilitando migrações e intercâmbios com os países limítrofes, e o possível confronto entre o "eu" e o "outro" que o espaço da fronteira possibilita. ${ }^{42}$ As fronteiras são reconhecidas principalmente como zonas que possibilitam trocas de lealdade, saberes e linguagens entre cidadãos distintos, podendo propiciar alguns conflitos e complexibilidade dos Estados-Nação. A permanente vigilância do território nacional passou, também, a exigir uma colonização militar.

No século XVIII, a ocupação da região Norte, especificamente da Amazônia foi ganhando forma, e a principal característica foi o processo de militarização regional. A Colônia Agrícola, articulada com a presença de uma guarnição militar, tornaram-se faces complementares da ocupação portuguesa. Nesse contexto, merece destaque a figura do colono e militar, destinados a agir nesses lugares estratégicos. ${ }^{43}$

É importante registrar a posição institucional do Exército, dentro da política de Estado do Império, no século XIX, com relação ao tema, apresentada no relatório do Ministro da Guerra, em $1857,{ }^{44}$ que defende a escolha desses locais para colonização militar. Era necessário privilegiar as regiões de fronteiras, os lugares onde se estabeleceriam núcleos de povoações, localizadas nas áreas remotas centrais e despovoadas. Somente os indivíduos habituados a resistir às privações, à obediência passiva, adquirida pelos severos hábitos da disciplina militar suportariam essa primeira realidade e contato com o território desconhecido.

Como diz o relator: A escolha desses pontos é, por via de regra, em nossas fronteiras ou em alguns centros, onde se tem accumulado vagabundos e malfeitores, que ameação a segurança e a propriedade dos habitantes dos povoados mais próximos. ${ }^{45}$ Tais colônias seriam, portanto, criadas com objetivos preponderantemente militares, ainda que nelas se encontrassem elementos econômicos de produção agrícolas e de criação de animais. Seriam colônias para atuar na segurança e na defesa, que garantissem o desenvolvimento das povoações locais e a soberania nacional.

\footnotetext{
${ }^{42}$ BARTH, Fredrik. O Guru, o Iniciador e Outras Variações Antropológicas. Rio de Janeiro, Contra Capa Livraria, 2000

${ }^{43}$ GOMES, Flávio dos Santos (Org.). Nas terras do Cabo Norte: fronteiras, colonização e escravidão na Guiana brasileira, séculos XVIII e XIX. Belém: Ed. UFPA, 1999, p. 14.

${ }^{44}$ BRASIL. Arquivo Histórico do Exército. Relatório do Ministério da Guerra, 1857.

${ }^{45}$ Ibidem, p. 45.
} 
Como exemplo dessa política, na região Norte do Brasil, especificamente na Província do Pará, no século XIX, quando se iniciava a consolidação do Segundo Reinado foram fundadas três colônias militares ${ }^{46}$ marcando o momento de estabilidade nacional: a Colônia Militar Pedro II, inaugurada isoladamente, em 06 de maio de 1840, na margem esquerda do rio Araguari (atual estado do Amapá); a Colônia Militar de São João D’Araguaia, fundada em 1851, na margem esquerda do rio Araguaia, na confluência com o rio Tocantins; e a Colônia Militar de óbidos á margem esquerda do rio Amazonas, fundada pelo Capitão do Imperial Corpo de Engenheiro Marcos Pereira de Salles, que recebeu a ordem do Presidente da Província, ${ }^{47}$ em 1854 . Com certeza, a implantação dessas colônias militares, embasadas a partir de 1850 por uma política imperial de segurança, também faz parte da história da colonização do sertão norte brasileiro, assim como as colônias ocupadas por imigrantes europeus no Amazonas e no Pará, tanto no Império como na República, já mencionadas na primeira parte desse texto. ${ }^{48}$

Nos anos 1850 foram criadas vinte e uma colônias militares no Brasil, distribuídas do Rio Grande do Sul à província do Pará. Antes mesmo, no Pará foi instalada a Colônia Militar Pedro II (1840). Esse número, extenso para a época, de colônias militares fundadas na segunda metade do século XIX revela uma política do Estado imperial, apoiada em três instrumentos legais:

1. Lei N. 555, de 15 de junho de $1850, \S 5^{\circ}$, Art. $11^{\circ}$ - distribuição do orçamento do Império para o ano financeiro de 1850 e 1851, autorizando o Poder Executivo a estabelecer onde convier, presídios e colônias militares dando-lhes a mais adequada organização;

2. Lei N. 601, de 18 de setembro de 1850 (Lei de Terras de 1850) - o artigo 12 previa o uso de terras devolutas para o assentamento de estabelecimentos públicos, e o artigo 18, autorizava o pagamento do deslocamento de colonos livres para serem empregados na formação de colônias nos lugares em que o governo achasse mais conveniente;

3. Decreto N. 1.318, de 30 de janeiro de 1854 (normatização da Lei de Terras de 1850) - o qual determinava no Art. 82, o estabelecimento de colônias militares

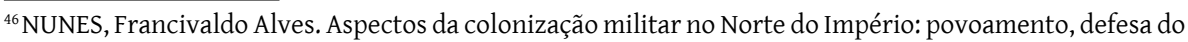
território e conflitos. In.: Cardoso, Alírio; Bastos, Carlos Augusto; e Nogueira, Shirley Maria Silva. (2015). História Militar da Amazônia: guerra e sociedade (séculos XVII e XIX). Curitiba: Editora CRV, 2015, p. 196.

${ }^{47}$ BRASIL. Coleção de Leis do Brasil. Decreto Imperial №. 1.363, de 8 de abril de 1854, que cria uma Colônia Militar na Vila de Óbidos da Província do Pará, e dá-lhe instruções.

${ }^{48}$ Os temas referente ás colônias militares precisam ser investigados com mais profundidade pela historiografia brasileira, até mesmo para a melhor compreensão do processo de colonização e de imigração, de forma geral, das áreas do Norte do país.
} 
na zona de dez leguas contígua aos limites do Império com Paízes estrangeiros, e em terras devolutas, que o Governo pretender povoar, estabelecer-se-hão Colonias Militares.

Ao que parece, essas recomendações para instalar as colônias militares nas áreas limites do Brasil com os países estrangeiros sinaliza que esse modelo de colonização era considerado uma estratégia de ocupação das fronteiras nacionais, evitando o avanço indesejável dos nossos vizinhos sobre o território brasileiro.

Para o diplomata Duarte da Ponte Ribeiro, ${ }^{49}$ que ajudou na formulação e execução da bem sucedida política de fronteiras do Império brasileiro, havia no final dos anos 1840, o abandono das nossas fronteiras. Em 1847, o tenente general Francisco José de Souza Soares D’Andrea (barão de Caçapava), aprontava o primeiro artigo de suas observações aos apontamentos sobre o estado das fronteiras no Brasil, do diplomata Duarte da Ponte Ribeiro, enfatizando as dificuldades na defesa do território, por conta da sua extensão, e o abandono das fronteiras brasileiras, apontando como solução a criação de colônias militares agrícolas nas fronteiras. Para o barão de Caçapava:

Não basta, também, ter pontos fortificados e destacamentos regulares por toda nossa extensa fronteira, é preciso desenvolver por toda ela uma população agrícola ou industriosa da melhor gente do país, nem será isto, de certo, útil ou proveitoso feito com colonos estrangeiros, ou mesmo com homens de cor. (Ribeiro, p.20)

Com esse posicionamento, percebemos que o projeto do general D’Andrea enfatizava, que não seria apenas a presença militar com patrulhamento que garantiriam a proteção das extensas fronteiras brasileiras. Para o militar, deveria ser implantada uma colonização eficaz, na qual os colonos povoariam, produziriam e defenderiam os limites nacionais. Como vimos anteriormente, essa proposta foi implantada nas margens do rio Araguari, Amazonas e Araguaia, com a fundação das Colônias Militares Pedro II, óbidos, e São João D'Araguaia. As Colônias Militares deveriam ser povoadas com população branca e indígena, que seriam recrutadas pelo Estado ou pelos colonos, como forma de ocupar, produzir e defender as fronteiras Norte do Brasil. ${ }^{50}$

A instalação de colônias militares em toda a extensão do território brasileiro, no século XIX, fez parte do esforço estatal de dominar regiões marcadas

\footnotetext{
${ }^{49}$ RIBEIRO, Duarte da Ponte. Apontamentos sobre o estado das fronteiras no Brasil. Apontamentos sobre o estado da Fronteira do Brasil em 1844, em adiantamento à memória de 1842 sobre limites do Império. Rio de Janeiro: Comissão demarcadora de limites, 1844, p. 19.

${ }^{50}$ SILVA, Rafale Amaro da. Colônia Militar Pedro II: nação e civilização na fronteira norte do Brasil. Dissertação de Mestrado. Belém: UFPA, 2013, p. 20.
} 
pela existência de tensões de várias naturezas: com pequenos agricultores, escravos fugidos, escravos libertos, indígenas e estrangeiros. Os presidentes de Províncias utilizavam as tropas localizadas na região como apoio à segurança e à defesa territorial.

Como vimos, no Império, com sua estrutura administrativa centralizadora, cabia ao governo legislar e executar os assuntos relacionados à imigração e à colonização das fronteiras. Essas estruturas administrativas aprofundaram-se ainda mais na República, com a autonomia estadual.

O regime federativo republicano retirou do governo central essas duas atribuições. A autonomia dos Estados foi construída gradativamente ao longo dos anos 1890 , principalmente, com a Constituição Federal de $1891^{51}$ que passou aos estados o domínio das terras devolutas. Essas terras era um dos principais recursos das políticas de colonização fundadas na pequena propriedade.

Ao longo dos anos 1890, o Congresso Nacional legitimou a legislação sobre imigração, uma prerrogativa dos Estados da federação, deslocando do governo federal para o governo estadual, as atribuições de administrar a contratação de imigrantes e empreender as políticas de colonização. Ao governo federal restou o papel de controle dos portos e fronteiras, o recebimento e hospedagem dos imigrantes que desembarcavam no porto do Rio de Janeiro, e o transporte dos imigrantes do porto até os núcleos coloniais organizados nos Estados.

Essa nova organização administrativa das políticas públicas gerou dois problemas que facilitaram a criação do Serviço de Povoamento. O primeiro foi a questão relacionada aos tratados, acordos e proteções internacionais aos imigrantes, que exigia a articulação entre os chefes de estados dos países envolvidos e seus representantes ministeriais, ação que contrariava o que estava definido na lei (CF de 1891). O segundo problema está relacionado com a dificuldade da maior parte dos governos estaduais em construir estruturas de imigração e colonização que pudessem substituir as estruturas do governo federal herdadas do Império. ${ }^{52}$

Jair de Souza Ramos ao analisar a criação e atuação do Serviço de Povoamento do Solo Nacional, ${ }^{53}$ agência do Ministério da Agricultura, Indústria

\footnotetext{
${ }^{51}$ Art. 64, da Constituição Federal de 1891. Disponível em: <http://www2.camara.leg.br/legin/fed/consti/1824-1899/constituicao-35081-24-fevereiro-1891-532699-publicacaooriginal-15017-pl.html>. Acesso em 02/10/2016.

${ }^{52}$ RAMOS, op. cit., p.58.

${ }^{53}$ O Serviço de Povoamento do Solo Nacional. Decreto N. 6.455, de 19 de abril de 1907. Disponível em: <http://www2.camara.leg.br/legin/fed/decret/1900-1909/decreto-6455-19-abril-1907-502417-publicacaooriginal-1-pe.html>. Acesso em 28/10/2016.
} 
e Comércio (no período de 1907 a 1930), através das políticas federais de imigração e colonização, define as ações do poder tutelar público sobre a formação do Estado brasileiro. A função essencial da agência era introduzir os imigrantes no interior do Brasil, como pequenos proprietários rurais, determinando o povoamento do solo nacional. Uma ação administrativa que se ligava ao movimento imigratório do país, realizada através da intervenção do governo federal..$^{54}$

É importante frisar que as ações colocadas em práticas pela agência articulam-se com outros agentes sociais envolvidos com a imigração e com a colonização, e estão descritas nos relatórios oficiais do Serviço de Povoamento. ${ }^{55}$

A atuação da agência envolvia interesses do governo federal na promoção do serviço de povoamento do solo nacional, que em parte foi conseguido mediante acordo com os governos estaduais, empresas de viação férrea e de navegação fluvial, companhias ou associações outras, e particulares, observadas as garantias necessárias a sua regularidade..$^{56}$

De um modo geral podemos ressaltar o caráter minucioso do documento. O Decreto N. 6.455 era composto de 138 artigos distribuídos ao longo de quatro títulos. O primeiro título dedicado às definições gerais sobre o Serviço de Povoamento do Solo Nacional; o segundo referente à colonização; o terceiro à colonização; e o quarto, referente às disposições gerais, aquelas que não se enquadram nos títulos anteriores.

Ao investigar mais detalhadamente o decreto de regulamentação do Serviço de Povoamento observamos o estabelecimento de regras explícitas quanto ao padrão do imigrante que o governo federal desejava para povoar o solo brasileiro. Deveriam ter menos de sessenta anos, não sofrerem de doenças contagiosas, não exercerem profissão ilícita, não serem reconhecidos como criminosos, desordeiros, mendigos, vagabundos, dementes ou inválidos.

Os imigrantes poderiam chegar aos portos brasileiros à custa da União, dos Estados da federação, de terceiros ou com o pagamento da sua passagem. As passagens pagas no Brasil seriam de $3^{\mathrm{a}}$ classe desde o porto de embarque até o Rio de Janeiro ou qualquer outro porto nacional, em que houvesse montado o serviço de recepção e hospedagem para imigrantes.

\footnotetext{
${ }^{54}$ RAMOS, op. cit., p.51.

${ }^{55}$ Esses documentos podem ser acessados pelo seguinte link: Disponível em: <http://www.crl.edu/brazil/ ministerial/agricultura>. Acesso em 28/10/2016.

${ }^{56}$ BRASIL. Arquivo Histórico do Exército. Coleção de Leis do Brasil. Art. 1º, do Decreto N. 6.455, de 19 de abril de 1907.
} 
A definição de um padrão mínimo de qualidade do imigrante era contextualizada pela necessidade do Estado de criar um povo com padrões aceitáveis de civilização, decorrendo daí essas condições impostas que segregavam os indivíduos indesejáveis pela sociedade. Essa prática discriminatória já vinha ocorrendo em outros momentos históricos, como no final do século XIX, quando o Brasil teve que resolver o problema da substituição da mão-de-obra escrava negra pelos imigrantes.

Pelo Decreto N. 6.455, de 19 de abril de 1907, aos imigrantes produtivos que se dedicassem a qualquer ramo da agricultura, da indústria, do comércio, da arte ou da ocupação útil, era garantido o direito pleno da sua atividade, da inteira liberdade de trabalho, desde que não houvesse ofensa à segurança, a saúde e aos costumes nacionais. A liberdade de crença e de culto também era garantida, além do gozo de todos os direitos civis atribuídos aos brasileiros conforme a Constituição Federal. Com o Artigo $3^{\circ}$ do Decreto, o governo federal tinha por objetivo definir a condição de cidadania aos estrangeiros que chegavam ao Brasil para trabalhar, o que não os eximia dos deveres atribuídos aos brasileiros e de serem penalizados por ofensa aos costumes públicos.

Outra preocupação regulamentada pelo Decreto N. 6.455, foi quanto à política de colonização. Pelo Art. 5ํㅡㄹ a definição de Núcleo Colonial era a reunião de lotes, medidos e demarcados, de terras escolhidas, férteis e apropriadas à agricultura, à indústria agrícola ou pecuária, em boas condições de salubridade, com abundância de água potável para as diversas necessidades da população, contendo cada um deles suficiente área para o desenvolvimento do trabalho do adquirente, servidos por viação capaz de permitir o transporte cômodo e fácil, em favorável situação econômica. Ou seja, era uma definição que não se aplicava aos possíveis lotes localizados no sertão norte e centro-oeste brasileiro. No máximo, no interior do sudeste e sul brasileiro.

Para tanto é importante entender nessa discussão a função de cada participante nacional na fundação dos núcleos coloniais. À União deveria auxiliar os Estados na fundação; aos Estados fundar colônias com ou sem o auxílio do Estado; nesse caso a escolha da localidade recairia sobre os seus interesses domésticos envolvendo cada região; e às empresas de viação férrea, empresas de navegação fluvial, Companhias, Associações, ou particulares fundar com ou sem auxílio da União e dos Estados, atendendo aos seus interesses.

No entanto, a União poderia intervir na fundação de núcleos coloniais por empresas de viação férrea, navegação fluvial, Companhias, Associações ou particulares, mesmo que não recebessem auxílios oficiais do governo federal, 
quando entender ser preciso instituir providências reguladoras do serviço e medidas repressivas de abusos.

Além disso, a fundação de núcleos coloniais, sob a administração direta da União e auxílio do Estado interessado, seguiria a seguinte regra:

1. A União faria a escolha da localidade e efetuaria a formação do Núcleo.

2. Em terras devolutas ou propriedade do Estado, o governo federal entraria em acordo com o respectivo governo no sentido de lhe ser cedido a área para a formação do núcleo.

Neste caso, o governo estadual auxiliaria a discriminação, se preciso, nos termos da sua legislação de terras e permitiria que fossem efetuados os trabalhos preparatórios e definitivos, tais como: estudos preliminares para a melhor repartição dos lotes, e para o traçado das linhas de comunicação interna e externa; medição e demarcação dos lotes rurais; obras de saneamento, quando necessárias; construção de casas, estradas e caminhos; preparo, em cada lote rural, da área destinada ás primeiras culturas; organização da sede do núcleo; e localização dos imigrantes.

Quando os lotes estivessem medidos e demarcados, conforme a regra acima ocorreria à efetiva cessão ao governo federal, que deveria vender aos imigrantes, ou utilizá-los em proveito do núcleo. Além disso, se as terras fossem de particulares, seriam adquiridas amigavelmente, por compra ou convenção, ou desapropriadas pelo governo estadual, realizando a União os trabalhos preparatórios e definitivos.

O governo estadual deveria fornecer gratuitamente aos imigrantes ferramentas e sementes, como auxílio ao primeiro estabelecimento, podendo também a União conceder iguais favores, além de outras vantagens. O Estado poderia prestar quaisquer auxílios em benefícios aos imigrantes independente dos concedidos pela União, e instituir prêmios de incentivo à ocupação do solo.

A escolha da localidade dos núcleos coloniais seria feita mediante prévio estudo regional. Pela legislação estudada, a preferência para implantação das colônias seriam as localidades reconhecidamente salubres. Em Estados onde não existissem colônias antigas ou núcleos coloniais de agricultores estrangeiros, o governo federal poderia adotar providencias excepcionais, quando indispensáveis para garantia da formação do primeiro núcleo em condições propícias ao seu desenvolvimento, servindo de centro de atração para o estabelecimento de crescente número de imigrantes..$^{57}$

${ }^{57}$ BRASIL. Arquivo Histórico do Exército. Coleção de Leis do Brasil. Art. 47º do Decreto N. 6.455, de 19 de abril de 1907. 


\section{Considerações finais}

Em relação às ações intervencionistas do Estado com face à colonização e à imigração, na região Norte do Brasil, foi possível verificar certas intencionalidades ao se promover estas políticas, como a ocupação do espaço ao longo das fronteiras terrestres com a América do Sul, que antes pertenciam à Espanha; a preservação da autonomia política, através da manutenção da soberania sobre o território que passou a ser reconhecido internacionalmente; 0 reconhecimento de um vasto território desconhecido no interior do Brasil; e o processo de integração sertão-litoral via processo de colonização e imigração.

A implantação das colônias militares pode ser compreendida no contexto de um propósito estatal em promover a ocupação territorial, e tornar os ocupantes desses espaços colonos produtivos, a partir de um regime militarizado, baseado na disciplina e em normas jurídicas próprias para os militares. Um instrumento para criar as condições de produtividade, em um ambiente hostil e isolado, um movimento de povoamento, de segurança e de defesa territorial, que exigiam dos colonos a superação das dificuldades impostas pelo espaço.

Por fim, é importante registrar, que o Estado incentivou, divulgou e colocou em prática políticas de imigração, para a criação de colônias, para povoar as áreas do interior, assim como estimulou a chegada de milhares de imigrantes espontâneos. A região de fronteiras, por sua vez, exigiu a permanente vigilância do território nacional e, consequentemente, coube à colonização militar fazer parte desse processo, que é bem mais complexo, e exige ainda, vários estudos complementares para entender essa colcha de retalho, que é o processo de formação territorial e social brasileiro.

Artigo recebido para publicação em 12/02/2017

Artigo aprovado para publicação em 21/04/2017 